\title{
Nurturing Citizenship in Higher Education: Public Achievement-style Education at Tokai University
}

\author{
Mayuko Horimoto* \\ Sachi Ninomiya-Lim ${ }^{* *}$
}

\begin{abstract}
The aim of this paper is to examine the possibility of how higher education can develop citizenship education within Japan. For this purpose, we will explore the background and history, the definitions, and the big picture of curricula as well as the goals of Tokai public achievement-style education as citizenship education, and its practices since the program commenced in 2017. Also, we try to identify successful key factors and some future challenges of citizenship education in higher education. As a result, we conclude that Public Achievement is not merely a set of educational methods, but a philosophy that values self-directed learning by individual citizens and encourages their authentic participation in creating a collective learning culture. To facilitate citizenship education further, the university also needs to create a learning culture to value this authentic participation of students, faculty, and staff in operating its organization and surrounding society.
\end{abstract}

Keywords: citizenship education; public achievement; higher education, community-based learning

\section{Introduction}

During the last decade, it has been widely stressed in Japan that "nurturing citizens" while considering the characteristics of $21^{\text {st }}$ century society and youth is one of the most important goals for higher education (MEXT 2008). However, there are relatively few higher education institutes that focus on citizenship in their education, and few examples of citizenship education have been reported (Sasai \& Nakamura, 2013). Tokai University, one of the largest universities in Japan, with around 30,000 students in total, has a history of providing citizenship education since its foundation in 1946. After almost seven decades, in 2013, it

* Tokai University, Japan

e-mail: mayuko.horimoto@tokai-u.jp

** Tokai University, Japan

e-mail: sachinl@tokai.ac.jp 
has begun to restructure its model of citizenship education based on the concepts and methods of "Public Achievement" (PA), a model of youth-led civic education. PA, based on free spaces and public work, is the wellspring of the new transdisciplinary field of civic studies, which disseminates resources for civic life and citizen action (Boyte, 2018, September). According to Boyte, who led the development of PA (2018, September), for a positive future of democracy, we need citizens who can talk and think well about what it means to be a citizen in a democracy, having the requisite skills and forming habits to put strong citizenship into practice. Thus, this paper examines how higher education in Japan can develop citizenship education, infusing PA concepts and methods based on Tokai's experience. For this purpose, first, we describe the background, history, and definition of citizenship education at Tokai University. Second, we set out the big picture of the curricula, as well as the goals of Tokai PA-style education. Thirdly, we explore the program's practices since it commenced in 2017. Finally, referring to the idea and concept of PA as citizenship education, we present the challenges and possibilities of PA-style education at Tokai University and identify the key factors for its success as well as future challenges for citizenship education as part of higher education.

\section{The History of Citizenship Education at Tokai University}

Tokai University, since its foundation in 1946, has been closely linked with the concept of the "folk" high schools of Denmark (Folkehøjskole in Danish). Dr. Shigeyoshi Matsumae, the founder, was a champion of the Danish philosopher N. F. S. Grundtvig (1783-1872), who advocated the Folkehøjskole system. Inspired by Grundtvig's philosophy, the university's mission from the outset has been to nurture youth as local and global citizens. Dr. Matsumae used the phrase "Chikyu Shimin" to describe global citizens in Japanese. He aimed to develop global citizenship in higher education (Boyte, 2019).

In 2006, Tokai University founded the Student Project Center with the educational mission to foster three competencies for social participation: the abilities to cooperate with others, deal with challenging issues, and accomplish goals. The Center later added another competency, the ability to think autonomously. Its primary role has been to provide financial, technical, and personnel support for student projects, selected based on students' applications each year. These projects provide an opportunity for students to acquire experientially these four competencies through activities they plan and implement on their own, with advice from faculty and staff. In their projects, students work to tackle social issues while interacting with others, including people from outside the university. Through such activities, they develop themselves as individual citizens. As of July 2019, there are 40 projects with 1,535 registered students at seven campuses throughout the country. In the past 13 years, issues addressed in the projects have ranged from the global in nature to those focused on local communities. Thus, the projects have produced domestic and international achievements and facilitated the development of local and global citizens.

In addition to supporting student projects, the Center has provided courses as part of undergraduate programs for students in all faculties and departments. These courses, with titles such as "Introduction to Competency in Cooperating with Others (or the three other listed competencies)" and "Exercise for Competency in Dealing with Challenging Issues (or the 
three other listed competencies)" have been aimed at developing the above four social competencies. The courses are open to all students, including those who do not participate in the student projects, to nurture these competencies as local and global citizens.

Based on the experience of the Student Project Center, Tokai University launched a project called "Promotion of the Center of Community (COC)" in 2013, funded by the Ministry of Education, Culture, Sports, Science and Technology. The funding was aimed at supporting the promotion of community-oriented education, research, and social contribution throughout the university (MEXT, 2013). The university recognized the strong link between its original mission to nurture local and global citizens and the aim of COC in encouraging community-oriented education. While its working group was exploring effective models of this education to develop the four competencies and citizenship of students, they encountered the concept of "Public Achievement (PA)", developed as an advanced form of youth citizenship education since 1990, primarily at the University of Minnesota in the United States (Augsburg University n.d., Boyte 2015).

\section{Tokai University's New Initiative: PA-style Education}

PA is a practice of political and social participation that is aimed at nurturing the motivation of citizens alongside the skills they need to build a democratic society. This is achieved by creating opportunities for authentic participation (Furuta 2015). Thus, PA education activities provide students with opportunities for true participation, creating public spaces in society as critical spaces (Kodama 2003). In the critical space of PA education activities, when teachers experience conflicts and tensions with students, they can deconstruct power and transform themselves as political coordinators (Kodama, 2003). Thus, the critical space is a place where students and faculty can learn from each other cooperatively. Boyte calls such spaces "free spaces," stressing that the culture of learning in free spaces creates ways to bridge the "traditional" and "modern" in educational styles and ways of thinking and acting (2018). Such learning opportunities empower students to feel that "I can actually change things if I try" (Donovan, 2014). In addition, PA is an "educational approach that encourages the students' self-directed learning" (Donovan, 2014). Young people (students) play leadership roles and "adults" - including faculty and staff - are there in a support role (i.e., coaches, coordinators or information providers). Students experience self-directed learning by resolving public problems or issues on their own. Furthermore, PA encourages the university to go beyond its boundaries and collaborate with communities to nurture citizenship values among young people (Erlanson \& Hildreth, 1998).

Based on this concept, Tokai University started developing "PA-style" education as part of its COC project, mentioned above. Its aim has been to promote further cooperation with the local community to create opportunities for students to develop as local and global citizens, who can participate in resolving public issues of the local and global community. Based on an in-depth review of the PA literature and practices developed by American universities, the working team created a framework for PA-style education at Tokai. They defined it as developing active citizens who can work with others to meet challenges and solve public problems at the local or global level. To achieve this purpose, the principal goals were set as follows: learning empirically how to co-create a democratic society through delibera- 
Figure 1: The Big Picture of the PA-style Education System at Tokai University

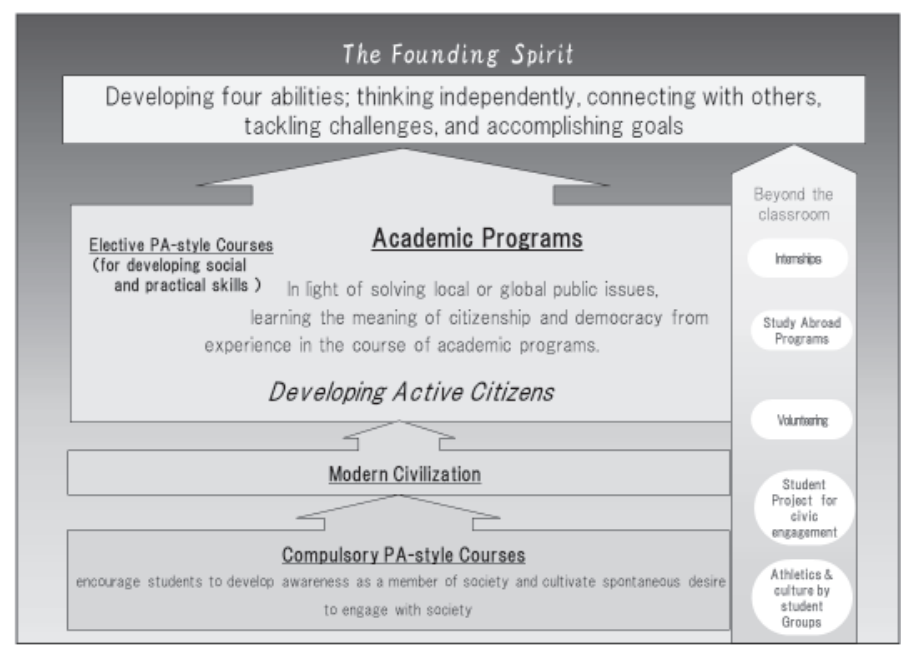

tion and project-based learning and developing social and practical skills such as active listening, imagining and creating, connecting problems to larger issues (i.e., seeing the "big picture"), defining a problem, defining a project, building consensus, deliberating, evaluating a project effort, and facilitating meetings as an active citizen. This PA-style education was built upon the philosophy of PA as a theoretical framework, rather than emulating its original educational methodology. The PA-style courses are designed to connect students' self-interest with their public lives, and to encourage their civic engagement to solve public issues, including participation in student projects and their wider society. To support students learning "how to learn" in an active, self-directed manner, the courses apply active learning methods including collaborative learning and learning through debates, interviews, group discussions, presentations and roleplay. In terms of the university organization, the Center for Liberal Arts was established in 2017, reforming the former Liberal Arts Education Center, to set up the Student Project Center as its sub-body, taking a role in designing and implementing university-wide PA-style education as the core of the university's liberal arts education.

In the 2018 academic year, Tokai University launched its PA-style education curriculum as an initiative to promote further citizenship education for its 30,000 students at seven campuses (Fig. 1 and Table 1). The new curriculum includes four basic PA courses - "Citizenship", "Volunteers", "Understanding Local Communities", and "Understanding Global Communities" - that are compulsory for the first-year students of all departments across twenty faculties, except for medical students. In addition, those students who seek to develop their social participation competencies and citizenship further can proceed to advanced PA courses, which provide an opportunity to explore further public issues of their interest, and to plan and implement their activities for solving such issues, or to reflect on their experiences in their own student project activities.

For the compulsory basic courses, students are divided into classes consisting of around 60 students from two or three different departments. In addition to the faculty of the Center for Liberal Arts, lecturers in different faculties who are in their first or second year at Tokai are assigned to these courses, to share the educational philosophy of PA as a common value 
Table 1: Public Achievement-style Education Courses at Tokai University ${ }^{*}$ One 100-minute class is offered per week. One semester consists of 14 weeks.

\begin{tabular}{|c|c|c|c|}
\hline Category & Courses & Credits & Duration* \\
\hline $\begin{array}{l}\text { Compulsory/ basic PA } \\
\text { courses }\end{array}$ & $\begin{array}{l}\text { Citizenship } \\
\text { - Volunteers } \\
\text { anderstanding Local Communities } \\
\text { - Understanding Global Communities }\end{array}$ & $\begin{array}{l}1 \\
1 \\
1 \\
1\end{array}$ & 7 weeks \\
\hline $\begin{array}{l}\text { Elective/ advanced PA } \\
\text { courses }\end{array}$ & $\begin{array}{l}\text { Public Work A/B } \\
\text { - Public Skills A/B } \\
\text { Coaching Practice } \\
\text { - Project Practice }\end{array}$ & $\begin{array}{l}2 \\
2 \\
1 \\
2\end{array}$ & 14 weeks \\
\hline
\end{tabular}

across the university. The Center for Liberal Arts provides faculty development workshops to these lecturers to share methods and skills to facilitate the courses. Each lecturer designs a course based on the guidelines prepared by the center, including ideas based on their own specialties and interests. The main objectives of the introductory courses are to facilitate students' understanding of basic concepts in relation to PA, and to encourage them to recognize their potential as active citizens. To reach these objectives, lecturers combine multiple educational methods such as lectures, discussions, and presentations.

The elective, advanced courses are smaller in size, with 20-50 students per class. The faculty of the Center for Liberal Arts lead these courses, designing them to develop students' competencies as local and global citizens in more practical settings. The themes and topics to be covered vary according to the lecturer's specialties and the students' interests.

Furthermore, Tokai also seeks to infuse the PA concept into professional education throughout degree programs. It requires transformation not only of pedagogy but also the organizational culture of faculties, which is a critical challenge.

\section{PA-style Education in Practice}

This section introduces how PA-style education is practiced, focusing on one compulsory basic course and one elective advanced course as examples.

First, "Understanding Local Communities", one of the four compulsory basic PA courses, is aimed at promoting students' understanding of the functions, values, characteristics and issues of local communities from a public perspective and facilitating their interest in, and awareness of, participating in sustainable community development as a citizen. The theme of the course is stipulated in the syllabus as "To understand issues faced in a community as a basis for living - focusing on XX". Each faculty member in charge of this course inserts a topic in relation to their specialty and interest to replace "XX". The topics that have been addressed include "Sustainable Development Goals", "Sports and Health", "IT", "Waste Issues", "Character of a Community," and "Child-raising". The model schedule and content of this course, as written in the guidelines, are shown in Table 2. The course begins with a workshop for students to reflect on their own experiences living in local communities at different stages of their lives, and to share these reflections with others. After a lecture on the diverse challenges local communities currently face from both domestic and global view- 
Table 2: Model Schedule and Contents of "Understanding Local Communities"

\begin{tabular}{|c|l|}
\hline Week & Content of the weekly class \\
\hline 1 & $\begin{array}{l}\text { Orientation/Communities and Me } \\
-\quad \text { Understand the aim, schedule and evaluation standards of the course } \\
-\quad \text { Understand the concept and importance of "communities" and recognize oneself as a member of a } \\
\text { community }\end{array}$ \\
\hline 2 & $\begin{array}{l}\text { Issues in Communities } \\
-\quad \text { Learn about issues faced by present communities }\end{array}$ \\
\hline 3 & $\begin{array}{l}\text { Solving Issues in Communities } \\
-\quad \text { Learn about actions to solve issues in a community } \\
-\quad \begin{array}{l}\text { Recognize the importance of collaboration among multiple actors in a community and that of one's own } \\
\text { potential to participate in such collaboration }\end{array}\end{array}$ \\
\hline 4 & $\begin{array}{l}\text { Group Discussion: Issues in Communities } \\
-\quad \text { Discuss issues in a community from the public perspective } \\
-\quad \text { Experience collaborative learning }\end{array}$ \\
\hline 5 & $\begin{array}{l}\text { Group Discussion: Solving Issues in Communities } \\
-\quad \text { Discuss solutions for issues in a community and the role of young people/students in such solutions } \\
-\quad \text { Experience collaborative learning }\end{array}$ \\
\hline 6 & $\begin{array}{l}\text { Group Presentation: Issues and Solutions in Communities } \\
-\quad \text { Share group presentations of public issues and possible solutions in a community } \\
-\quad \text { Experience collaborative learning }\end{array}$ \\
\hline 7 & $\begin{array}{l}\text { Reflection } \\
-\quad \begin{array}{l}\text { Reflect on learning throughout the course and reconsider the importance of a community and one's role } \\
\text { therein }\end{array}\end{array}$ \\
\hline
\end{tabular}

Table 3: Examples of Students' Comments at the End of the "Understanding Local Communities" Course (originally in Japanese)

"I have never really thought about my hometown, especially about its good side. But now I'm away from my home, and during this course, I was able to understand its good aspects and issues from an objective viewpoint."

"I have realized that I, too, can contribute to tackling the issues of a local community. I have also learned that people have different opinions about issues, and they are all not wrong, so it is important to accept others' opinions and ask questions. I hope to practice how to express opinions and ask questions in various discussions that I will experience in the future."

"We were made aware, from various perspectives, of what we should and can do for sustainable development, what issues our local communities are facing, and what ideas we have in this regard, throughout this course. As we repeated groupwork, I gradually got used to discussion and exchanging opinions with others - it was such a good experience."

"The course gave me an opportunity to practice thinking about problems and causes around me and in other local communities, seeing the big picture, building opinions, expressing them to others who may have different thoughts, and listening to others. I hope to continue expressing my own opinions while respecting those of others in my university life and even after graduation."

"I learned that groupwork deteriorates when the members do not share the same motivation. I want to keep in mind that it is important to listen to others in a serious manner, and to respond in some way."

points, students explore issues and resources in their communities, list local stakeholders, and suggest possible collaborative solutions, both as individuals and in groups. The groupwork is also aimed at providing students with an opportunity to experience collaboration within a team. At the end of the course, students reflect on their learning throughout the course. Ex- 
amples of the comments written by students are shown in Table 3. These indicate that the students have taken the course as an opportunity to explore issues and solutions for their communities, to learn the value of collaboration with others, and to recognize their own power to participate in such collaboration.

While the compulsory PA courses are conducted in large classrooms, the advanced courses are more flexible, to allow collaboration with actual communities. For instance, one of the authors promotes students' participation in community development challenges in the course "Public Skills". The course takes around 20-30 students per semester and brings them out to Miyamatsu-cho, Hiratsuka City, a suburban community near Tokai University's Shonan campus, the largest of its seven campuses. The town of Miyamatsu is the site of a major housing and commercial development. In the midst of critical change, the community is facing issues such as a communication gap between old and new residents, the increasingly dysfunctional status of the traditional community association, the decline of the local shopping area, and the lack of preparation for increasingly threatening natural disasters, among others. In this course, students propose and implement a project as a team with local stakeholders of the community to overcome these issues and enable transformation toward sustainability and civic engagement. In 2018, in the first semester, the students presented their proposal to organize a community-building event utilizing public parks in the area. In the second semester, the students collaborated with the community to hold an event in one of the parks to facilitate community relationships with a particular focus on preparation in order to mitigate disaster risks. This became an opportunity for students to participate in creating a sustainable community as citizens.

\section{Challenges and Possibilities}

In the process of developing PA-style education at Tokai University, several challenges that have to be overcome and keystones for successful citizenship education have come to light. In this section, we explore them from the perspective of developing a culture of free spaces, stressing the value of students and faculty learning from one another cooperatively. There are seven challenges to this process, as discussed below.

First, while Tokai University runs PA-style education as a university-wide program, the size of the classes, especially for basic compulsory courses, makes it a challenge to ensure the quality of education for each student. PA-style education requires faculty to play their role as facilitators or coaches to guide students' self-directed learning. The number of students per class for the basic courses has been lowered from 80 in 2018 to 60 in 2019; however, it is still difficult for one lecturer to provide enough attention and support to each student. As a solution, "Coaching Practices," which is an elective PA course, aims to develop students as coaches to support other students in basic courses. The establishment of this peer-support system among students will lead to more effective citizenship education for students in basic courses and those in "Coaching Practices." At the same time, the development of methods and skills by the faculty also needs to be facilitated further to support students to evolve as self-directed learners so that they can not only effectively learn through courses but also create their own careers as citizen professionals to engage in building a sustainable society after their graduation. 
Second, it has been a challenge to achieve the aims of the PA courses within their duration. Seven weeks for basic courses and 14 weeks for advanced courses may not be enough for students to understand fully the concept of PA and to experience authentic participation. It is important to coordinate learning experiences throughout different PA courses, specialized courses in degree programs, and the students' life outside university courses and possibly even after graduation, as one holistic process.

Third, ensuring the participation and self-directed learning of students is a challenge, particularly in compulsory courses. Compulsory registration in courses does not indicate authentic participation, which PA values; it may even mean compulsory involvement against their will for some students. Faculty need to continue seeking ways to connect the course aims and contents with the interests and motivations of students from different backgrounds.

Fourth, in relation to the previous point, valuing different interests and ways of learning among students in the class is another challenge. While all the students are required to take the basic PA courses, participation in groupwork can be an extreme challenge for some students, for instance those with special needs. The university currently offers those who drop out of the basic courses the opportunity to take the same course in a smaller-sized class, in which students are given special treatment. Therefore, we need to consider further PA-style educational methods that meet the different needs of diverse students.

Fifth, establishing the appropriate means for evaluating students' learning in the PA courses has also been a challenge. We need to continue the discussion on reflecting the philosophy of PA in the evaluation methodology.

Sixth, connecting students' learning in the PA courses with actions in the student projects and wider society is an important challenge. It is necessary to design mechanisms carefully to realize such connections, emphasizing the process of self-directed learning in classes for students to recognize the influence of their actions in solving social problems and their personal development.

Lastly, to reach the ultimate goal of inculcating the PA philosophy in education across the university as a whole, transforming the organizational culture will become a critical challenge. PA is not merely a set of educational methods but a philosophy for valuing self-directed learning and authentic participation in creating a future as a collective of individual citizens. To facilitate PA-style education further, the university needs to develop its culture so as to value authentic participation by students, faculty, and staff, by operating its organization in relation to the surrounding society.

As for keystones for conducting successful PA-style education in universities, first, faculty and staff need to continuously communicate the message that the students are the central component of the learning process, connecting their education with each student's unique interests. Second, cooperative learning of the philosophy, concepts, and methods of PA and citizenship education among faculty and staff need to be facilitated further (Boyte et al., 2018) for them to keep in mind the importance of a free space for learning (Horimoto, 2017). Third, the university needs to set up support systems for students to keep learning to connect their skills and abilities with their future career as citizen professionals (Boyte et al., 2018). It is also important to encourage the faculty and staff to live as citizen professionals. 


\section{Conclusion: Implications for Citizenship Education in Higher Education}

In this article, we found that in tackling social issues in PA-style education courses, students cooperated with each other to discuss how to find and solve these problems. However, participating in the provided courses does not immediately mean that students will be able to find or solve problems in the real world. The university must continue supporting the learning processes of students, to nurture their authentic citizenship, while steadily building up their experience over the four years of the bachelor degree. The goals of citizenship education include empowering students to identify public problems or issues, and to think about them and act upon them in their own lives. The experience of resolving problems and utilizing the knowledge and information acquired also leads to "learning how to learn". Given that we have just begun the process, and thorough evaluation of the PA-style education is not yet possible, it is also necessary for the university to establish an evaluation system for its citizenship educational programs.

Creating an organizational learning culture for implementing citizenship education is also crucial. As mentioned above, infusing the PA concept into professional education throughout degree programs requires transformation not only of pedagogy but also of the organizational culture of faculties, which is a critical challenge. When conducting classes that are closely related to the interests of individual students, there is a compelling need to develop the understanding and skills of faculty to be able to work with a wide variety of students. For this purpose, the role of the management is vital in creating a learning culture throughout the university as a workplace for faculty and staff, enabling faculty and staff to have sufficient free spaces to learn and communicate for providing high-quality classes and courses.

\section{References}

Augsburg University (n.d.) Public Achievement. Retrieved September 13, 2019, from https://inside. augsburg.edu/publicachievement/

Boyte, H. (Ed.) (2015). Democracy of education: Public work, citizenship, \& the future of colleges and universities. Tennessee: Vanderbilt University Press.

Boyte, H. (2018). Awakening democracy through public work: Pedagogies of empowerment. Tennessee: Vanderbilt University Press.

Boyte, H., Takahashi, F., Horimoto, M., \& Ninomiya-Lim, S., (2018, September). Research Session 2. In Kodama, S. \& Kikuchi, K. (Chair), Education and politics in a global age. Research session conducted at the $77^{\text {th }}$ annual conference of the Japanese Educational Research Association, Miyagi.

Boyte, H. (2018, September). Preparing Citizen Professionals - New Dimensions of Civic Education in Higher Education. Paper presented at the meeting of University of Tokyo Symposium, Tokyo.

Boyte, H. (2019, August). New dimensions of civic education in the age of post-truth, In T. Muramatsu (Chair), Education and democracy in an age of post-truth. Symposium conducted at the WERA Focal Meeting, Tokyo.

Erlanson, B. \& Hildreth, R. (1998). Building Worlds, Transforming Lives, Making History: A Coach's Guide for Public Achievement 2nd ed., Minneapolis: Center for Democracy and Citizenship.

Donovan, D. (2014, February). What does public achievement look like in practice, In To-collabo program "The Possibility of Public Achievement-style Education" Symposium conducted at Tokai University, Tokyo.

Furuta, Y. (2015). America Hinkonchiiki no Gakko ni okeru Citizenship Kyoiku no Igi to Kanousei"Public Achievement" Dounyu Jirei no Bunseki wo toshite" (Significance and potentiality of citizenship education in schools in poorer areas in the United States - through analysis of case stud- 
ies of "public achievement"). Nihon Kyouiku Keiei Gakkai Kiyo (Bulletin of the Japanese Educational Management Society), 57, 110-124. (Japanese).

Kodama, S. (2003). Citizenship no Kyouiku Shiso (Educational Thought in Citizenship). Tokyo: Hakutaku-sha, (Japanese).

Horimoto, M. (2017). Public Achievement gata Kyouiku Dounyu heno Torikumi (Approach to the introduction of public achievement style education), Shakai Kyouikugaku Kenkyu (Japanese Journal of Adult and Community Education), 53, 39-40. (Japanese).

Horimoto, M. \& Ninomiya-Lim, S. (2018, September). Public Achievement-style Education at Tokai University - Background and Practice, In S. Kodama \& K. Kikuchi (Chairs), Education and Politics in a Global Age. Symposium conducted at the $78^{\text {th }}$ Annual Conference of Japanese Educational Research Association.

Sasai, H. \& Nakamura, K. (2013). Syougaigakusyu no Innovation (Innovative Lifelong Learning). Tokyo: Tamagawa University Press, (Japanese).

Ministry of Education, Culture, Sports, Science and Technology (MEXT). (2019, September 11). Gakushikatei no Kochiku ni Mukete (The Central Council for Education "Toward the construction of undergraduate education"). Retrieved from http://www.mext.go.jp/component/b_menu/shingi/ toushin/_icsFiles/afieldfile/2008/12/26/1217067_001.pdf . (Japanese).

Ministry of Education, Culture, Sports, Science and Technology (MEXT). (2019, September 11). Chi no Kyoten Seibi jigyou ( "Promotion of the Center of Community" (COC) project). Retrieved from http://www.mext.go.jp/a_menu/koutou/kaikaku/coc/__icsFiles/afieldfile/2014/01/22/1342759_02.pdf. (Japanese). 